\title{
A REVIEW OF THE EFFECTS OF FEEDING PROPYLENE GLYCOL TO EARLY LACTATING DAIRY COWS
}

\author{
Nicolaj Nielsen and Klaus Lønne Ingvartsen \\ Department of Animal Health and Welfare, Danish Institute of Agricultural Sciences, P. O. Box 50, \\ DK-8830 Tjele, Denmark.
}

\section{Introduction}

In recent years, the interest in feeding propylene glycol (PG) to Danish dairy cows has grown among dairy farmers, veterinarians and advisers. This is due to an increased supply of products which, by virtue of their PG content, claim to increase milk yield and/or prevent ketosis. PG has been used for nearly 50 years in the treatment of ketosis. The objective of this report was to review the effects of PG on the fermentation pattern in the rumen, blood and liver parameters, feed intake and performance in order to evaluate whether PG is able to improve the negative energy balance and prevent ketosis in cows in early lactation.

\section{Results and discussion}

PG decreases the $\mathrm{C} 2 / \mathrm{C} 3$-ratio in the rumen of cows and heifers, because some of the PG is fermented to propionate. Most of the PG is absorbed from the rumen or intestine without being fermented. In early lactating cows and fasted heifers, PG decreases the proportion of butyrate in the rumen. PG in a dose of 200-700 g/day has no effect on the $\mathrm{pH}$ in the rumen of mid-lactating cows.

Feeding 200-900 g of PG daily to early lactating cows and fasted heifers has shown a tendency to increase the concentrations of plasma glucose and insulin and decrease the concentrations of NEFA and $\beta$-hydroxybutyrate. The inconsistent results across experiments in the observed responses for these metabolites may be explained by differences in the dose of PG and the time from feeding PG to the time of blood sampling. PG fed prepartum has also been shown to decrease the lipid content of the liver postpartum. It seems likely that PG decreases the mobilisation of adipose tissue and acts antiketogenically in cows in negative energy balance.

Very few experiments have examined the effect of PG on feed intake, but those that do exist show that PG does not affect feed intake in early and mid-lactating cows. Feeding PG to mid lactation cows causes an unchanged or decreased milk yield and energy corrected milk yield (ECM). A metaanalysis across 3 experiments using cows in early lactation indicated that the feeding of PG has a significant $(\mathrm{P}<0.05)$ effect on milk yield and fat content, while there is no effect on the protein content of the milk. The metaanalysis indicated that feeding $300 \mathrm{~g}$ of PG/cow/day increases milk yield by 2.1 $\mathrm{kg}$, reduces fat content by 0.35 percentage units, and increases ECM yield by $1.8 \mathrm{~kg}$. We have found no studies that have investigated the effect of feeding PG on the incidence of clinical ketosis in periparturient dairy cows.

\section{Conclusion}

Few experiments have examined the effects of PG on physiological parameters, feed intake and milk production in early lactating dairy cows. Existing studies indicate that PG increases the milk production, reduces the mobilisation of adipose tissue and acts antiketogenically. However, there is no documentation that PG decreases the incidence of ketosis. 